\title{
Desafios à Integralidade da Assistência em Cuidados Paliativos na Pediatria Oncológica do Instituto Nacional de Câncer José Alencar Gomes da Silva
} Challenges to the Integrality of Assistance in Palliative Care in the Pediatric Ward of the National Cancer Institute José Alencar Gomes da Silva Desafíos a la Integralidad de la Asistencia en Cuidados Paliativos en la Pediatría Oncológica del Instituto Nacional de Cáncer José Alencar Gomes da Silva

Gabrieli Branco Martins; Senir Santos da Hora

\section{Resumo}

Introduçáo: A integralidade da assistência em cuidados paliativos na oncologia pediátrica apresenta desafios na medida em que há pouca oferta desse tipo de cuidado e, principalmente, no que se refere à interlocuçáo de políticas públicas que auxiliem no processo de desospitalização. Objetivos: Identificar e refletir sobre os desafios elencados pela equipe multiprofissional da pediatria oncológica do INCA, que interferem na integralidade da assistência em cuidados paliativos. Método: Pesquisa qualitativa com base na hermenêutica dialética e no referencial teórico marxista com participação de nove profissionais de nível superior da equipe multiprofissional da clínica de pediatria oncológica do INCA. Os dados foram coletados por meio de entrevista, entre agosto e dezembro de 2016. Resultados: Identificaram-se seis categorias empíricas que se apresentam como desafios à integralidade da assistência em cuidados paliativos: dissociação entre cuidado curativo e cuidado paliativo; centralidade da prática médica; organização do serviço; estrutura física e recursos humanos; capacitação em cuidados paliativos; e articulação com a rede de serviços de saúde. Conclusáo: A integralidade na assistência em cuidados paliativos na pediatria do INCA constitui-se um grande desafio em consequência da dicotomia entre assistência curativa e paliativa; do persistente modelo hospitalocêntrico, dificultando a desospitalização; da organização da rotina do serviço imprópria à comunicação e troca de saberes entre a equipe multiprofissional; da estrutura física e recursos humanos insuficientes, incluindo a falta de capacitação para essa modalidade de assistência; além da fragmentação da rede de serviços de saúde.

Palavras-chave: Assistência Integral à Saúde; Cuidados Paliativos; Oncologia; Pediatria; Institutos de Câncer.

\footnotetext{
${ }^{1}$ Assistente Social pela Universidade Federal Fluminense (UFF). Especialista em Oncologia pelo Instituto Nacional de Câncer José Alencar Gomes da Silva (INCA). Mestranda em Saúde Pública pela Escola Nacional de Saúde Pública da Fundação Oswaldo Cruz (Ensp/Fiocruz).E-mail: gabrielimartins@id.uff.br. ${ }^{2}$ Assistente Social do INCA. Mestre em Serviço Social e Desenvolvimento Regional pela UFF. Doutoranda em Política Social pelo Programa de Pós-Graduação em Serviço Social da Universidade do Estado do Rio de Janeiro (PPGSS/UERJ).E-mail: senirsantos@hotmail.com. Endereço para correspondência: Gabrieli Branco Martins. Rua Miguel de Frias, 41 - apartamento 1604 - Bloco 3 - Icaraí. Niterói (RJ), Brasil. CEP: 24220-008. E-mail: gabrielimartins@id.uff.br.
} 


\section{INTRODUÇÃO}

O câncer infantojuvenil é considerado um evento raro, apesar de ser um problema importante no âmbito da Saúde Pública, em consequência dos seus profundos impactos físicos, psicológicos e sociais ${ }^{1}$. Segundo o Instituto Nacional de Câncer José Alencar Gomes da Silva (INCA), o câncer em crianças e adolescentes corresponde de $1 \%$ a $3 \%$ de todos os tumores no Brasil. Para o período de 2016 e 2017, estimou-se a incidência de 12.600 casos de câncer compreendendo essa faixa etária no país, com exceção dos tumores de pele não melanoma ${ }^{2}$. Apesar de o tratamento ser considerado promissor quando realizado precocemente, o câncer pediátrico ameaça à vida, e cerca de $30 \%$ dos pacientes atendidos na pediatria do INCA vão a óbito em razão da progressão da doença ${ }^{3}$.

Segundo a Organização Mundial da Saúde, o cuidado paliativo pediátrico (neste trabalho, utilizaram-se os termos "infantojuvenil", "em crianças e adolescentes" e "pediátrico" como sinônimos) é uma modalidade de assistência essencialmente multiprofissional que prevê o cuidado ativo e total para as crianças e adolescentes que vivenciam uma doença que ameaça à vida. $\mathrm{O}$ cuidado ativo e total significa um cuidado intenso e global para os pacientes e seus familiares, com suporte premente a todos os aspectos que abarcam a vida do indivíduo por meio de uma perspectiva holística, envolvendo questôes físicas, psicológicas, sociais e espirituais. O cuidado paliativo infantojuvenil deve ser iniciado logo após o diagnóstico e concomitante ao tratamento curativo, preconizando o alívio do sofrimento e a autonomia da família com a participação do paciente (a partir da capacidade evolutiva de tomada de decisóes deste último) e, principalmente, o controle da dor, independentemente de sua natureza ${ }^{4}$.

Para Silva e Hortale, "Paliar é uma dimensão crítica do cuidado em saúde" $\mathrm{e}$ evidencia a noção ampliada de saúde, pois seu olhar vai além das questóes estritamente clínicas, visando ao atendimento integral. Segundo o Dicionário de Educação do Profissional em Saúde 7 , atendimento integral está relacionado ao princípio da integralidade do Sistema Único de Saúde (SUS), que prevê um conjunto articulado de açóes e serviços de saúde e busca "reconhecer, para além das demandas explícitas, as necessidades dos cidadáos no que diz respeito à sua saúde" 7 . A integralidade como princípio do SUS pressupóe a concretização da interdisciplinaridade e da intersetorialidade entre a saúde e as demais políticas públicas ${ }^{8}$.

A interdisciplinaridade é entendida como uma integração horizontal entre os diferentes saberes na área da saúde, sob a perspectiva da superação de qualquer visão fragmentada e/ou dicotômica frente à busca pela totalidade do conhecimento e das conexôes mais profundas entre as ciências9. Já a intersetorialidade é definida como a integraçâo entre as políticas sociais e entre as açốes e serviços de saúde, com "interfaces entre setores e instituições governamentais (e não governamentais), visando ao enfrentamento de problemas sociais complexos que ultrapassem a alçada de um só setor de governo ou área de política pública" ${ }^{\prime 1}$. Sendo assim, em ambas as concepções estão presentes, para sua consecução, o imperativo da integralidade como princípio doutrinário do SUS. Dessa forma, açôes contínuas de intersetorialidade e interdisciplinaridade são necessárias no atendimento em saúde, especialmente na perspectiva da integralidade que o cuidado paliativo infantojuvenil alvitra ${ }^{7}$.

No INCA, pacientes adultos em cuidados paliativos sáo encaminhados para uma unidade dirigida especialmente para essa modalidade de atençáo, o Hospital do Câncer IV (HCIV), onde recebem tratamento paliativo da equipe multiprofissional especializada. Entretanto, para o público infantojuvenil (0 a 18 anos), os cuidados paliativos são realizados na clínica de pediatria por um profissional médico paliativista, não havendo uma equipe multiprofissional de referência para atuar nas especificidades deste tipo de cuidado.

A motivação pela abordagem paliativa às crianças e adolescentes originou-se em virtude da atuação na clínica de pediatria oncológica. As situaçóes vivenciadas no cotidiano de trabalho, assim como a organizaçáo institucional do INCA na clínica de pediatria oncológica, despertaram o interesse em identificar os desafios à assistência em cuidados paliativos.

Por conseguinte, o presente estudo visa a investigar os entraves ao cuidado paliativo pediátrico no INCA, respondendo à seguinte pergunta: "Quais são os desafios para a integralidade da assistência em cuidados paliativos na pediatria oncológica do INCA?”. A partir dessa questão norteadora e com base no imperativo da integralidade, objetiva-se identificar e refletir sobre os desafios da assistência em cuidados paliativos colocados pela equipe multiprofissional da pediatria do INCA.

\section{MÉTODO}

Trata-se de estudo qualitativo, que busca compreender os desafios para a integralidade do cuidado paliativo no contexto do serviço de pediatria oncológica do INCA. Este estudo foi realizado por meio de pesquisa de campo, no qual o material empírico produzido das entrevistas semiestruturadas com profissionais de saúde vinculados ao serviço foi analisado com base no referencial teórico marxista e na técnica de análise de dados hermenêutica-dialética.

A pesquisa de campo, realizada entre os meses de agosto e dezembro de 2016, no Serviço de Pediatria 
Oncológica do INCA, no Rio de Janeiro, teve a aprovação do Comitê de Ética em Pesquisa do INCA com o número do parecer 1.630.330 (CAE 56561716.8.0000.5274 em 10/7/2016).

Os dados foram produzidos por meio de entrevistas semiestruturadas, a partir de uma amostra não probabilística de nove profissionais, um de cada categoria de nível superior, pertencente à equipe multiprofissional da clínica de pediatria oncológica do INCA. A escolha dos profissionais deu-se por indicação das respectivas chefias de cada categoria profissional, uma vez que não há uma equipe dedicada exclusivamente aos cuidados paliativos na clínica pesquisada. A amostra teve apenas uma recusa, contudo, esse fato não causou prejuízo à coleta de dados, uma vez que outra profissional da mesma categoria e com experiência no cenário de estudo foi indicada pela chefia e aceitou participar. As entrevistas foram audiogravadas e realizadas em espaço reservado nas dependências do INCA por uma das autoras.

Os pontos abordados nas entrevistas seguiram rigorosamente o roteiro semiestruturado submetido e aprovado pelo Comitê de Ética e Pesquisa do INCA. São eles: interesse em trabalhar na pediatria; interesse em trabalhar na oncologia; entendimento por cuidado paliativo na atenção oncológica infantojuvenil; papel da equipe multiprofissional no cuidado paliativo; intervenção no cuidado paliativo; abordagem em cuidados paliativos na pediatria do INCA; efetivação de atendimento interdisciplinar; indicação de cuidados paliativos; abordagem com a família; princípios paliativistas na organização do processo de trabalho; rede intersetorial de cuidados paliativos; desafios e possibilidades para o atendimento integral.

Assegurou-se o sigilo aos participantes ao não se identificar a categoria profissional nas citaçóes das falas no corpo do trabalho. Esse cuidado foi de extrema relevância, uma vez que, na clínica de pediatria do INCA, existem categorias profissionais que contam com apenas um profissional na assistência, portanto sinalizar as categorias colocaria em exposiçấo alguns autores dos depoimentos.

Em relação aos riscos aos entrevistados, evitou-se a ocorrência de possíveis constrangimentos ao profissional que não soubesse a proposta da pesquisa, tendo um momento de explicação prévia sobre o assunto, assim como a assinatura do Termo de Compromisso Livre Esclarecido (TCLE). Para preservar o sigilo das informaçôes e possíveis interrupçóes que pudessem atrapalhar o momento da coleta de dados, as entrevistas foram agendadas conforme disponibilidade do entrevistado e realizadas em sala reservada exclusivamente para essa finalidade.

A análise dos dados foi realizada pelas autoras deste artigo, em conjunto, entre os meses de dezembro de 2016 e fevereiro de 2017, por meio da técnica hermenêutico-dialética e com base no referencial teórico marxista. Essa técnica possibilita uma interpretação da realidade, pois articula a perspectiva compreensiva da hermenêutica com a criticidade do método dialético. Essa técnica de análise considera o sujeito como um ser histórico, tendo a linguagem como núcleo central, entendendo os fenômenos por intermédio da vida cotidiana e levando em consideraçáo a cultura e o contexto dos atores sociais ${ }^{11}$.

Já o referencial teórico marxista ressalta que a construção do conhecimento parte da realidade concreta de sucessivas abstraçóes que, por meio da razão dialética, apreende o desenvolvimento histórico e as contradiçóes das relaçóes sociais ${ }^{11}$. Ou seja, ainda que a realidade seja produto das relaçôes sociais e da objetivação do ser social, é necessário percorrer um caminho de análise que permita conhecer profundamente sua estruturaçáo e funcionamento, dado que a experiência exclusiva do cotidiano náo permite seu entendimento. Essa concepçáo teórica exige superar quaisquer determinismos interpretativos, pois uma análise concreta e objetiva implica uma interrelação dialética entre estrutura e sujeito ${ }^{12}$.

Nessa direção, a análise de dados foi realizada considerando a seguinte trajetória metodológica: ordenação dos dados, classificação dos dados e análise final.

Para a etapa de organização dos dados, realizou-se a identificação do material empírico coletado e a transcrição das entrevistas (totalizando 59 laudas), com a leitura preliminar do material, assim como a primeira organização dos diferentes dados contemplados no campo de estudo.

$\mathrm{Na}$ classificação dos dados, as transcrições foram lidas exaustivamente, e os trechos com as estruturas relevantes e ideias centrais das falas dos entrevistados foram selecionados, agrupados e classificados a partir das categorias empíricas, nas quais as unidades de sentido eram semelhantes. Os critérios para inclusão e agrupamento das falas foram a recorrência, a expressividade e a relevância para compreensáo do objeto, quer por homogeneidade, quer por singularidade. Realizou-se o confronto dialético das ideias e posiçóes dos sujeitos que estabelecem relaçóes na abordagem em cuidados paliativos na pediatria oncológica, pela categoria analítica integralidade que constituiu o fio condutor deste estudo.

Nessa etapa, foram identificadas duas unidades de sentido: "Desafios na abordagem do cuidado paliativo pediátrico no INCA" e "Desafios institucionais na pediatria do INCA". A partir das unidades de sentido, foi possível a identificação das categorias empíricas, o que possibilitou uma primeira aproximaçâo com os achados da pesquisa visando à compreensão da lógica das falas recorrentes que estavam diretamente ligadas ao objeto de estudo. 
$\mathrm{Na}$ análise final, fez-se a articulação do material empírico e do referencial teórico, a partir da intersecção de diferentes olhares e falas com a interação entre as diferentes informações coletadas e as impressôes das pesquisadoras. Segundo Minayo ${ }^{13}$, é nessa fase que se dá "o verdadeiro movimento circular, que vai do empírico para o teórico e vice-versa, que dança entre o concreto e o abstrato, que busca as riquezas do particular e do geral"13, pois foi na análise final dos dados que se trabalhou mais intensamente as informaçóes obtidas junto ao referencial teórico marxista, favorecendo na compreensão do objeto estudado.

\section{RESULTADOS E DISCUSSÃO}

Como já exposto no método do estudo, ao todo foram realizadas nove entrevistas, com um profissional entrevistado em cada categoria de nível superior presente na clínica de pediatria oncológica do INCA: medicina; enfermagem; odontologia; serviço social; psicologia; fisioterapia; terapia ocupacional; fonoaudiologia e nutrição.

Todos os participantes eram do sexo feminino e graduaram-se entre o período de 1983 e 2006. Oito deles eram estatutários e apenas um tinha vínculo de contrato, com a média de 9,3 anos de serviço na instituição, incluindo extremos de três e 30 anos. Dos nove entrevistados, apenas três declararam ter realizado algum curso de especialização ou capacitação em cuidados paliativos.

A partir dessas informaçóes, pode-se refletir sobre a ausência de formação do profissional de saúde nessa área, visto que o cuidado paliativo é considerado uma modalidade de assistência recente no Brasil e possui desafios para sua concretização que partem desde escassez de políticas públicas nesse âmbito até o despreparo de profissionais para esse tipo abordagem ${ }^{14}$. O perfil da amostra indica que apenas $33,3 \%$ dos profissionais entrevistados possuem algum tipo de formaçáo em cuidado paliativo, apesar de atuarem numa clínica de oncologia pediátrica e possuírem uma média de 19 anos de formados.

Além disso, chama atenção o fato de a amostra ser composta exclusivamente por mulheres, refletindo uma construção histórica das relaçóes sociais de gênero, que naturaliza a mulher no papel de cuidadora ${ }^{15}$. Um exemplo disso é o resultado da pesquisa realizada no HCIV sobre o perfil, as condições de inserção e participação do cuidador junto ao paciente com câncer avançado, atendidos no INCA no período de agosto de 2003 e janeiro de 2004, que constatou que $96 \%$ dos cuidadores eram do sexo feminino ${ }^{16}$. Observa-se que o resultado ratifica a correspondência das desigualdades de gênero no âmbito do cuidado. Dessa forma, compreender a construçăo histórica do papel da mulher na sociedade é essencial na interpretação do perfil dos profissionais indicados para a realizaçáo deste estudo, uma vez que o senso comum estabelece o cuidado como tarefa inerente ao gênero feminino.

A respeito das limitaçóes desse estudo, evidencia-se que, assim como em toda pesquisa científica, o produto da realidade aqui investigada é resultado da compreensão e interpretação das pesquisadoras junto ao referencial teórico e analítico utilizado. Entretanto, em pesquisas de caráter qualitativo, em que as conclusóes são resultado de um caminho metodológico de análise e não de verificação de verdades primeiras, sua validação tende a ser questionada especialmente pelos seguidores da perspectiva positivista ${ }^{11}$. Dessa forma, reitera-se que as limitaçóes do estudo se relacionam à escolha da amostra, pois a pesquisa é restrita à equipe multiprofissional e existem outros atores envolvidos direta e indiretamente no processo de cuidado em saúde na clínica de pediatria oncológica do INCA que não fizeram parte do desenho dessa investigação como, por exemplo, os familiares, pacientes e gestores.

Justificando a escolha da amostra, vale ressaltar que este estudo parte do pressuposto que os profissionais presentes no cotidiano da clínica dominam a complexidade do tratamento oncológico infantojuvenil e, em razão das suas vivências, conhecem os desafios da assistência em cuidados paliativos nesse cenário. Nesse sentido, corrobora-se o que assevera Minayo quanto à construção do conhecimento a partir da pesquisa qualitativa "que tem como matéria prima as opinióes, crenças, valores, representaçôes, relaçôes humanas e sociais sob a perspectiva dos atores em intersubjetividade" 13 .

Destarte, a partir da análise dos dados conforme o caminho metodológico escolhido, foram selecionados 16 recortes de fala que melhor representam as unidades de sentido e as respectivas categorias empíricas encontradas. As duas unidades de sentido são: "Desafios na abordagem do cuidado paliativo pediátrico no INCA" e "Desafios institucionais na pediatria do INCA".

$\mathrm{Na}$ unidade "Desafios na abordagem do cuidado paliativo pediátrico no INCA", identificaram-se duas categorias empíricas: "Dissociação entre cuidado curativo e cuidado paliativo" e "Centralidade da prática médica". $\mathrm{Na}$ unidade de sentido "Desafios institucionais na pediatria do INCA", verificaram-se quatro categorias empíricas: "organização do serviço"; "estrutura física e recursos humanos"; "capacitação em cuidados paliativos"; e "articulação com a rede de serviços de saúde".

$\mathrm{Na}$ unidade de sentido "Desafios na abordagem do cuidado paliativo pediátrico no INCA", concentram-se 
as falas que reúnem informaçóes sobre as características do atendimento em cuidado paliativo prestado na clínica de pediatria do INCA.

$\mathrm{Na}$ unidade de sentido "Desafios institucionais na pediatria do INCA", concentram-se as falas que indicam os entraves em níveis organizacional e estrutural para realização dos cuidados paliativos na pediatria do INCA.

\section{DESAFIOS NA ABORDAGEM DO CUIDADO PALIATIVO PEDIÁTRICO NO INCA: DISSOCIAÇÃO ENTRE CUIDADO CURATIVO E PALIATIVO}

Segundo as entrevistadas, na maioria dos casos, a abordagem em cuidado paliativo na pediatria do INCA acontece quando a proposta curativa é exaurida, como exemplifica as falas dos participantes:

Pelas experiências que eu tive aqui, que eu já presenciei, geralmente acontece quando o paciente está muito grave, com a doença avançada e se interrompe um tratamento curativo (E.1).

Quando o cuidado com a intençáo curativa, que geralmente é exaustivamente tentado, não surte efeito. E infelizmente é assim, é dissociado do cuidado paliativo (E.7).

Quando a criança está em processo de morte-morrer, principalmente nas últimas semanas, é que a gente acaba dizendo, classificando em paciente paliativo e isso é muito ruim (E.1).

Para a Academia Americana de Pediatria ${ }^{17}$, com o avanço da doença e a consequente limitação das possibilidades de cura, a assistência em cuidados paliativos deve ser intensificada progressivamente.

Dessa maneira, não realizar medidas paliativas até que o tratamento curativo seja esgotado pode prejudicar na abordagem precoce de questóes delicadas, como a restrição ou supressão de tratamentos invasivos no fim da vida ${ }^{17}$.

Em recente pesquisa realizada com pacientes em cuidados de fim de vida na pediatria do INCA, constatou-se que os pacientes que receberam assistência de cuidados paliativos durante o tratamento tiveram melhores indicadores de qualidade de fim de vida, em comparaçáo aos que não receberam ${ }^{3}$.

Segundo Valadares, Mota e Oliveira ${ }^{18}$, no Brasil, ainda há preconceito sobre a restrição de tratamentos invasivos para os pacientes com doenças potencialmente fatais. No entanto, o atual Código de Ética Médica (CEM) ${ }^{19}$ dispõe, em seu artigo 41, sobre o dever do médico em oferecer cuidados paliativos aos pacientes com doenças incuráveis e terminais:
Nos casos de doença terminal, deve o médico oferecer todos os cuidados disponíveis sem empreender açóes diagnósticas ou terapêuticas inúteis ou obstinadas, levando sempre em consideração a vontade expressa do paciente ou, na sua impossibilidade, a de seu representante legal ${ }^{19}$.

\section{DESAFIOS NA ABORDAGEM DO CUIDADO PALIATIVO PEDIÁTRICO NO INCA: CENTRALIDADE DA PRÁTICA MÉDICA}

Outro desafio apontado como característico da abordagem em cuidado paliativo na pediatria do INCA foi em relação à ausência de trabalho interdisciplinar entre a equipe, pois as falas denunciam a centralidade da prática médica em relação aos demais trabalhadores da saúde:

No INCA, o cuidado paliativo é centrado na figura do médico. Eu não vejo muita interação. Acho que não existe. Deveria existir uma equipe de cuidados paliativos ou uma comissão de cuidados paliativos (E.9).

Você não consegue fazer cuidado paliativo sozinho. Se você tiver um médico, você năo faz cuidado paliativo, porque o cuidado paliativo precisa da interdisciplinaridade, das trocas de saberes. O cuidado paliativo precisa ter o seu lugar, está muito perdido (E.4).

A criança ou o paciente, ele não é em pedaços, na realidade ele existe como um todo. Entáo como o todo que o ser humano é, ele precisa de vários olhares para você poder trabalhar com uma melhor qualidade com esse paciente (E.6).

Um dos princípios dos cuidados paliativos pediátricos é a atuação em equipe interdisciplinar. A interdisciplinaridade se propóe a "ver o todo, não pelo somatório das partes que a compóem, mas pela concepção de que tudo sempre está em tudo, tudo repercute em tudo, permitindo que o pensamento ocorra com base no diálogo entre as diversas áreas do saber" ${ }^{20}$. A interdisciplinaridade não se impóe como uma proposta de aniquilamento das especializaçóes, mas como unidade de reciprocidade entre os diferentes saberes, sem a prioridade e hegemonia de uma especialidade e/ou categoria sobre outra?

\section{DESAFIOS INSTITUCIONAIS NA PEDIATRIA DO INCA: ORGANIZAÇÃOO DO SERVIÇO}

As entrevistadas relatam que a organização da rotina do serviço não prioriza uma comunicação da equipe multiprofissional sobre os casos, o que desvaloriza a compreensão sobre as representaçôes sociais que envolvem a história de vida dos sujeitos. 
Faltam condiçôes para que os profissionais discutam os casos. É necessário incluir uma rotina no fluxo de comunicação interdisciplinar e não somente no critério dos médicos [...] Não é porque a gente é multi [profissional] que tem esse olhar integral, acho que pra ser integral de fato tem que ter a inter [disciplinaridade]. E pra ter a inter, tem que ter possibilidades desses profissionais estarem se reunindo, possibilidades estruturais eu estou falando... com relação a RH [recursos humanos], com relação a espaço e tempo (E.8).

Aqui no INCA, a gente sabe que tem as rotinas institucionalizadas, a gente pode acessar o sistema e a gente tem lá as rotinas. Eu sinto falta de ter essas rotinas aqui, que seriam os protocolos de cuidado paliativo (E.1).

Parafraseando Campos ${ }^{21}$, só é possível construir mudanças nas práticas de saúde com a reestruturação no funcionamento dos serviços e mudanças dos profissionais que atuam nestes. Isto é, uma relação dialética de mudanças com as pessoas, com as estruturas e com as relações entre elas. É preciso, segundo o autor, conduzir mudanças institucionais a partir de novos modos de organização das práticas da clínica e da saúde pública, com alterações nas intervenções "dos profissionais de saúde, no qual o médico é o sujeito, ator primordial, determinante do processo de estruturação das práticas integrais de saúde"21.

\section{DESAFIOS INSTITUCIONAIS NA PEDIATRIA DO INCA: ESTRUTURA FÍSICA E RECURSOS HUMANOS}

As entrevistas evidenciam a falta de estrutura física e de recursos humanos compatíveis com uma assistência adequada em cuidados paliativos. $\mathrm{Na}$ análise dos dados, esse desafio se mostrou presente, conforme ilustrado a seguir:

Falta de um local físico para a internaçáo no momento do desfecho, uma enfermaria que fique somente crianças em cuidados paliativos (E.6).

Falta de um local específico para a terminalidade [...]. A gente chegou numa fase que $50 \%$ de ocupação na enfermaria é cuidado paliativo[...]. Todo o entorno de não ser um hospital específico para criança dificulta muito, até mesmo no processo de humanização. A gente tem que ter um espaço pra essa criança e esse espaço não é só físico, é um espaço filosófico, de filosofia da equipe (E.2).

O desafio é que são poucos profissionais, é um número muito grande de pacientes, então nem sempre funciona como deveria funcionar. Existe uma equipe, os profissionais atuam nas suas especificidades, mas nem sempre existe essa possibilidade dessa troca tấo concreta assim. Não por falta de vontade, mas por falta de tempo e de recursos humanos mesmo. Muito trabalho pra pouco profissional (E.3).

Essas falas elucidam os estudos de Mendes e Vasconcelos ${ }^{22}$, em relação à ausência de um serviço completo de cuidados paliativos no nível da assistência de média e alta complexidades, o que demonstra "um enorme descompasso dos serviços, uma vez que os pacientes internados nesse nível, com suas doenças crônicas evolutivas e terminais, são lançados à própria sorte, recebendo, muitas vezes, um tratamento indigno" 22 . Os autores citam como exemplo as unidades de terapia intensiva que acabam por oferecer aos pacientes, em fase terminal da doença, um tratamento invasivo e não resolutivo.

\section{DESAFIOS INSTITUCIONAIS NA PEDIATRIA DO INCA: CAPACITAÇÃO EM CUIDADOS PALIATIVOS}

A necessidade de capacitação é colocada como desafio à assistência em cuidados paliativos na clínica pesquisada. A qualificação é reiterada nas falas como determinante em dois aspectos: para o paciente e sua família, no sentido de oferecer uma assistência mais assertiva, e para o profissional que, ao se qualificar, influi nas relaçôes e condiçōes concretas de trabalho, pois se prepara para conviver da melhor forma com o sofrimento, a dor e a morte, conforme ilustram os depoimentos a seguir:

Deve ter uma preparação do profissional para lidar com o paliativo, pois a vivência é um pouco diferente, vamos dizer... espiritualmente falando. $\mathrm{O}$ profissional tem que se preparar porque a gente sofre muito (E.2).

Muitas pessoas entram aqui com uma visão muito curativa e vêm com isso da própria graduação e da experiência profissional. Entáo eu acho que falta capacitação nesse sentido (E.5).

Eu acho que a equipe deveria ser até preparada de uma forma psicológica para poder estar apta para fazer esse trabalho. [...] você precisa ter uma cabeça muito bem preparada pra ele discutir situaçóes de morte porque pro cara da assistência é traumático[...] (E.6).

O aprimoramento do cuidado em saúde possui relação direta com o fortalecimento da capacitação permanente dos profissionais como política de educação no SUS ${ }^{23}$. Não obstante, a educação permanente é apontada por Carvalho e Ceccim $^{24}$ como estratégia do SUS para a formação e o desenvolvimento de trabalhadores críticos e tecnicamente competentes para a saúde. A assistência em 
cuidado paliativo requisita atuação qualificada, na qual a partilha dos conhecimentos técnicos e científicos vai culminando na apreensão das dimensóes éticas da vida, do trabalho, do homem, da saúde e das relaçôes. Esse modelo de assistência exige dos profissionais novas competências que remetam direta, mas não exclusivamente, à pesquisa, à produção de conhecimento e às alternativas de intervenção na realidade social ${ }^{24}$.

\section{DESAFIOS INSTITUCIONAIS NA PEDIATRIA DO INCA: ARTICULAÇÃO DA REDE DE SERVIÇOS DE SAÚDE}

A fala das entrevistadas evidencia a fragmentação do SUS e indica novas tendências de parcerias e contratos de gestão realizados no campo da saúde, via implementação do modelo de Organizaçôes Sociais de Saúde na gerência da Estratégia Saúde da Família, como estímulo à terceirização e à privatização da rede pública, além da ideia de atenção básica como pacote mínimo de açôes voltadas para assistência aos pobres:

As redes de atenção à saúde, elas foram completamente fragmentadas. A privatizaçáo da gestão da atenção básica pelas OS [organizaçôes sociais] e o sucateamento do Estado. Você não tem pessoas concursadas nessas estratégias de saúde da família [...] O problema é que essa rede está deficitária por falta de pessoal. Essa é a fala dos pacientes: a dificuldade do paciente em retornar para a estratégia saúde da família (E.6).

A contrarreferência e referência... o ir e o voltar não existe, a gente sabe disso... E a desospitalização. Eu acho que desospitalizar é isso. Porque você, quando hospitaliza, vão ali a criança pequena, os pais... acho perfeito, especialmente a criança pequena se beneficia muito com a presença dos pais, mas você hospitalizou conflitos, pobreza, você hospitalizou tudo e de repente virou obrigação da saúde dar conta de absolutamente tudo, né. (...) A gente hospitaliza cronicamente a criança e a família e vira uma grande família e, com todas essas questôes permeando, nada mais acontece do que aumentar os conflitos entre a criança e a família (E.2).

Conforme apontam Mendes e Vasconcellos ${ }^{22}$, a interlocução das várias áreas de atenção à saúde constitui-se como principal desafio à efetivação de uma assistência em cuidados paliativos. Os autores mencionam a fragilidade da atenção básica e da média complexidade na garantia da assistência em cuidados paliativos, pois, na atenção básica, ainda que com a iniciativa recente da assistência em cuidados paliativos domiciliares, por meio do Programa Melhor em Casa, é tímido o impacto dessa proposta na cobertura da rede de atençáo do SUS.
A desospitalização, por meio da prestação da assistência em domicílio, constitui-se como um dos principais desafios aos cuidados paliativos, especialmente por causa da inoperância das ações intersetoriais ${ }^{25}$. Há notórias dificuldades no acesso a medicamentos, insumos, hospedagem e outros recursos necessários à desospitalização, sobretudo quando se analisa a assistência paliativa sob a ótica da integralidade e da humanização ${ }^{25}$.

Monnerat e Souza ${ }^{10}$, ao estudarem sobre os dilemas da integração das políticas sociais no Brasil, desde a inscrição da Seguridade Social na Carta Constitucional de 1988 à intersetorialidade, constatam que a contrarreforma do Estado atingiu a saúde por meio das proposiçôes de restrição do financiamento público; da dicotomia entre as açôes curativas e preventivas, com a persistência da concepção endógena prevalente e do paradigma biológico ainda hegemônico no campo e que se expressa na prática dos profissionais, principalmente na dificuldade estrutural de fixar médicos na equipe multiprofissional de saúde da família, em todo o território nacional.

\section{CONCLUSÃO}

A integralidade na assistência em cuidados paliativos na pediatria oncológica do INCA constitui-se um grande desafio. Sobre o atendimento prestado, evidencia-se uma dicotomia entre cuidado curativo e paliativo, dada a fragmentação desses momentos desde o diagnóstico; assim como a persistente centralidade da prática médica, que se revela como complicadora garantia da interdisciplinaridade. A organização do serviço na pediatria do INCA é também sinalizada como desafio, pois é vista como desfavorável à comunicação e troca de saberes entre a equipe multiprofissional. Do mesmo modo, são elencados como entraves a estrutura física imprópria ao cuidado paliativo; o número de recursos humanos insuficientes; a fragmentação da rede de serviços de saúde; e a falta de capacitação como estratégia para efetivação dessa modalidade de assistência.

O cuidado paliativo pediátrico no INCA possui desafios referentes à construção de estratégias para atuar nas múltiplas e complexas determinaçôes que o cuidado paliativo pediátrico envolve, visto os obstáculos na realizaçáo do cuidado paliativo desde o diagnóstico e na perspectiva da interdisciplinaridade. No aspecto organizacional, enfatiza-se que os desafios colocados no cenário estudado estão relacionados à falta de investimentos em estrutura física e em políticas públicas de promoção de saúde que visem a atuar de forma intersetorial na perspectiva da garantia da desospitalização, assim como a falta de incentivo na formaçáo e na gestáo da força de trabalho em saúde, pensadas sob as necessidades demandadas pelos cuidados paliativos pediátricos. 
Destaca-se que este estudo não pretende esgotar o assunto apresentado, mas sim fomentar a discussão sobre a valorização da assistência paliativa no campo oncológico e no universo infantojuvenil, tão marcado pelas suas particularidades.

\section{CONTRIBUIÇÕES}

Gabrieli Branco Martins colaborou na concepção, delineamento, coleta, análise e interpretação dos dados, redação do artigo e aprovação da versão a ser publicada. Senir Santos da Hora orientou e colaborou na concepção, delineamento, análise, interpretaçáo dos dados, redação do artigo e aprovação da versão a ser publicada.

\section{Declaração de Conflito de Interesses: Nada a Declarar.}

\section{REFERÊNCIAS}

1. Grabois MF. $\mathrm{O}$ acesso a assistência oncológica infantil no Brasil [tese]. Rio de Janeiro: Fundação Oswaldo Cruz, Escola Nacional de Saúde Pública; 2011.

2. Instituto Nacional de Câncer José Alencar Gomes da Silva. Estimativa 2016: incidência de câncer no Brasil. Rio de Janeiro: INCA; 2015.

3. Mattos DWG. Avaliação do cuidado de fim de vida dos pacientes pediátricos com tumores sólidos atendidos na Seção de Oncologia Pediátrica do Hospital do Câncer I do Instituto Nacional de Câncer José Alencar Gomes da Silva [dissertação]. Rio de Janeiro: Instituto Nacional de Câncer José Alencar Gomes da Silva; 2016.

4. World Health Organization. Definition of Palliative Care. $2^{\mathrm{a}}$ edition. Geneva: WHO; 2002.

5. Silva RCF, Hortale VA. Cuidados Paliativos oncológicos: elementos para o debate de diretrizes nesta área. Cad Saúde Pública. 2006;22(10):2055-66.

6. Ministério da Saúde (BR). Anais da $8^{\circ}$ Conferência Nacional de Saúde; 1986 mar 17-21; Brasília, DF. Brasília, DF: Ministério da Saúde; 1987.

7. Pereira IB, Lima JCF, organizadores. Dicionário da educação profissional em saúde. 2. ed. Rio de Janeiro: EPSJV; 2008.

8. Pinheiro R, Mattos RA. Cuidado: as fronteiras da integralidade. 3. ed. São Paulo: Hucitec; 2005.

9. Pereira PAP. A interdisciplinaridade das políticas sociais na perspectiva dialética. In: Monnerat GL, Almeida NLT, Rosimary GS, organizadores. A intersetorialidade na agenda das Políticas Sociais. Campinas: Papel Social; 2014. p. 23-29.
10. Monnerat GL, Souza RG. Da seguridade social à intersetorialidade: reflexôes sobre a integração das políticas sociais no Brasil. Rev Katálysis. 2011;14(1):41-9.

11. Minayo MCS. O desafio do conhecimento: pesquisa qualitativa em saúde. 14. ed. São Paulo: Hucitec; 2014.

12. Paulo Netto J. Introdução ao estudo do método de Marx. São Paulo: Expressão Popular; 2011.

13. Minayo MCS. Análise qualitativa: teoria, passos e fidedignidade. Ciênc Saúde Coletiva. 2012;17(3):621-26.

14. Brito MA, Soares EO, Rocha SS, Figueiredo MLF. Cuidados Paliativos em pediatria: um estudo reflexivo. Rev Enferm UFPE on line. 2015;9(3):7155-60.

15. Saffioti H. A mulher na sociedade de classes: mito e realidade. São Paulo: Expressão Popular; 2013.

16. Chaves ARM. O cuidador no provimento do cuidado ao paciente com câncer avançado no Instituto Nacional de Câncer [Dissertação]. Rio de Janeiro: Universidade do Estado do Rio de Janeiro; 2004.

17. Committee on Bioethics; Committee on Hospital Care. Palliative Care for Children. Pediatrics. 2000;106(2): 351-57.

18. Valadares MTM, Mota JAC, Oliveira BM. Cuidados paliativos em pediatria: uma revisão. Rev bioética. 2013;21(3):486-93.

19. Conselho Federal de Medicina. Resolução no 1931/2009. Diário Oficial da União. Brasília, DF, 24 set. 2009. Seção 1, p. 90.

20. Andrade RC. Interdisciplinaridade: um novo paradigma curricular. In: Goulart IB, organizadora. A educação na perspectiva construtivista: reflexóes de uma equipe interdisciplinar. Petrópolis: Vozes; 1995. p. 93-103.

21. Campos CEA. O desafio da integralidade segundo as perspectivas da vigilância da saúde e da saúde da família. Cienc Saúde Coletiva. 2003;8(2):569-84.

22. Mendes EC, Vasconcellos LCF. Cuidados paliativos no câncer e os princípios doutrinários no SUS. Saúde Debate. 2015;39(106):881-92.

23. Alves VS. Um modelo de educação em saúde para o Programa Saúde da Família: pela integralidade da atençâo e reorientação do modelo assistencial. Interface (Botucatu). 2005; 9(16):39-52.

24. Carvalho YM, Ceccim RB. Formaçáo e educaçáo em saúde: aprendizados com a Saúde Coletiva. In: Campos GWS, Minayo CMS, Akerman M, et al., organizadores. Tratado de Saúde Coletiva. São Paulo: Hucitec; 2006. p. 137-70.

25. Rabelo CAFG, Rodrigues PHA. Saúde da família e cuidados paliativos infantis: ouvindo os familiares de crianças dependentes de tecnologia. Cienc Saúde Coletiva. 2010;15(2):379-88. 


\section{Abstract}

Introduction: The integrality of palliative care in pediatric oncology presents challenges insofar as there is little supply of care, especially the demobilization process. Objectives: To identify and reflect on the challenges in search of a multiprofessional team of INCA pediatric oncology that interferes in the integrality of the resource in palliative care. Method: Qualitative research based on dialectical hermeneutics and Marxist theoretical reference, with the participation of nine professionals from the multiprofessional team of the INCA Pediatric Oncology Clinic. The data were collected through an interview between August and December 2016. Results: We identified six empirical categories that present as challenges to integrality in palliative care: dissociation between curative care and palliative care; centrality of medical practice; organization of the service, physical structure and human resources; instruction in palliative care; and Articulation with a network of health services. Conclusion: An integrality in palliative care assistance in the INCA pediatrics is abig challenge, due to the dichotomy between curative care and palliative care; the persistent hospital-centered model, making de-hospitalization difficult; an organization of the INCA pediatric service routine, signposted as improper to communication and flavors exchange among a multiprofessional team; an inadequate physical structure and human resources, including a lack of capacity building for the assistance modality; In addition to the fragmentation of the health services network.

Key words: Comprehensive Health Care; Palliative Care; Medical Oncology; Pediatrics; Cancer Care Facilities.

\section{Resumen}

Introducción: La integralidad de la asistencia en cuidados paliativos en la oncología pediátrica presenta desafíos en la medida en que hay poca oferta de ese tipo de cuidado, principalmente en lo que se refiere a la interlocución de políticas públicas que auxilien en el proceso de desospitalización. Objetivos: Identificar y reflexionar sobre los desafíos enumerados por el equipo multiprofesional de la pediatría oncológica del INCA que interfieren en la integralidad de la asistencia en cuidados paliativos. Método: Investigación cualitativa con base en la hermenéutica dialéctica y en el referencial teórico marxista con participación de nueve profesionales de nivel superior del equipo multiprofesional de la clínica de pediatría oncológica del INCA. Los datos fueron recolectados a través de entrevistas entre agosto y diciembre de 2016. Resultados: Se identificaron seis categorías empíricas que se presentan como desafíos a la integralidad de la asistencia en cuidados paliativos: disociación entre cuidado curativo y cuidado paliativo; centralidad de la práctica médica; organización del servicio, estructura física y recursos humanos; capacitación en cuidados paliativos; y articulación con la red de servicios de salud. Conclusión: La integralidad en la asistencia en cuidados paliativos en la pediatría del INCA constituye un gran desafío, debido a la dicotomía entre asistencia curativa y paliativa; el persistente modelo hospitalocéntrico, dificultando la desospitalización; la organización de la rutina del servicio en la pediatría del INCA, señalada como inapropiada a la comunicación e intercambio de saberes entre el equipo multiprofesional; la estructura física y recursos humanos insuficientes, incluyendo la falta de capacitación para esa modalidad de asistencia; además de la fragmentación de la red de servicios de salud.

Palabras clave: Atención Integral de Salud; Cuidados Paliativos; Oncología Médica; Pediatría; Instituciones Oncológicas. 